\title{
Herpes simplex encephalitis with relapse
}

\author{
M G Pike, C R Kennedy, B G R Neville, M Levin
}

\begin{abstract}
Three children are described in whom herpes simplex encephalitis (HSE) followed a clearly biphasic course. The secondary deterioration may be due to a resurgence of the viral infection and calls into question the adequacy of current treatment regimens for HSE. Alternatively, a postinfectious neuroallergic process may be active in which case immunomodulatory treatment might be more appropriate than further antiviral treatment.
\end{abstract}

There are a number of reports of adults who experienced herpes simplex encephalitis (HSE), that was proved at biopsy, four days to two months after satisfactory response to antiviral treatment. ${ }^{1-3}$ Until recently, only three paediatric cases of relapse have been described ${ }^{4-6}$ of which two ${ }^{4} 5$ were thought to represent postinfectious neuroallergic phenomena. The third case occurred after herpes simplex virus (HSV) type 2 infection in a 6 week old baby and was therefore probably of congenital origin. These have now been supplemented by the description of a further five cases in whom there was evidence to suggest a postinfectious phenomenon (M A Carpentier-Barthez et al, paper presented at the European Federation of Child Neurology Societies, Paris 1991). We describe three children who presented with HSE at our hospitals within a two year period and who all experienced a clearly biphasic illness.

\section{Case reports}

CASE 1

A previously well 11 year old boy presented to his local hospital with fever, headache, confusion, and dysphasia. His cerebrospinal fluid was examined (table) and a diagnosis of viral meningitis was made. Over the next few days he became more confused and developed generalised tonic-clonic seizures. A computed tomogram showed predominantly left sided temporal lobe low densities. Treatment was started from the third day of his illness with penicillin and cefotaxime for one week and with intravenous acyclovir (45 mg/kg/day) and dexamethasone for three weeks. His level of consciousness improved and the fever resolved though he was left with a mild right hemiplegia and dysphasia. Eight days after the end of his treatment his fever and headache returned and there was an increase in his dysphasia. Examination of the cerebrospinal fluid was repeated (table) and transfer to a tertiary centre was arranged.

On arrival he was found to be drowsy but rousable with a mild right hemiplegia and a moderate global dysphasia. Extensive microbiological investigations (including cerebrospinal fluid viral culture) were negative with the exception of HSV serology (table). An electroencephalogram (EEG) showed widespread slow activity over the left hemisphere with some intermittent repetitive sharp waves over the left sylvian region, although there were no definite findings to indicate HSE. A computed tomogram showed an enhancing left temporal lesion.

He was treated with a further course of acyclovir $\left(1.5 \mathrm{~g} / \mathrm{m}^{2}\right.$ surface area/day) followed, in view of the possibility of a resistant organism, by a course of intravenous vidarabine. On this regime his fever, consciuus level, and hemiplegia improved. After discharge he is left with a mild right facial weakness and a mild persisting dysphasia.
Hospital for

Sick Children and

Institute of Child Health,

London

M G Pike

B G R Neville

$M$ Levin

Southampton General Hospital

C R Kennedy

Correspondence to:

Dr M G Pike,

Department of Paediatrics,

John Radcliffe Hospital,

Headington,

Oxford OX3 9DU.

Accepted 17 July 1991

(Arch Dis Child 1991;66:1242-4)

Findings in blood and cerebrospinal fluid in the three children during the first and second phase of the illness

\begin{tabular}{|c|c|c|c|c|c|c|}
\hline $\begin{array}{l}\text { Day } \\
\text { (phase of } \\
\text { illness) }\end{array}$ & $\begin{array}{l}\text { Blood }(B) \text { or } \\
\text { cerebrospinal fluid } \\
(C S F)\end{array}$ & $\begin{array}{l}\text { Protein } \\
(\mathrm{g} / \mathrm{l})\end{array}$ & $\begin{array}{l}\text { Glucose } \\
\text { (mmolll) }\end{array}$ & $\begin{array}{l}\text { White cells } \\
\left(\times 10^{\circ} / l\right) \\
(\% \text { lymphocytes })\end{array}$ & $\begin{array}{l}\text { Red blood } \\
\text { cells }\left(10^{\circ} / l\right)\end{array}$ & HSV titre \\
\hline $\begin{array}{r}\text { Case 1 } \\
3(1) \\
3(1) \\
13(1) \\
1(2) \\
1(2)\end{array}$ & $\begin{array}{l}\text { B } \\
\text { CSF } \\
\text { B } \\
\text { B } \\
\text { CSF }\end{array}$ & $\begin{array}{l}\overline{0.31} \\
\overline{-} \\
1.46\end{array}$ & $\frac{\overline{5}}{3 \cdot 9}$ & $\begin{array}{l}-15(62) \\
- \\
19(100)\end{array}$ & $\begin{array}{l}-^{2} \\
{ }\end{array}$ & $\begin{array}{l}<1 / 8 \\
<1 / 2 \\
<1 / 8 \\
=1 / 64 \\
=1 / 16\end{array}$ \\
\hline $\begin{array}{c}\text { Case 2 } \\
1(1) \\
15(1) \\
15(1) \\
10(2) \\
19(2)\end{array}$ & $\begin{array}{l}\text { CSF } \\
\text { B } \\
\text { CSF } \\
\text { CSF } \\
\text { CSF }\end{array}$ & $\begin{array}{l}\text { 'Normal' } \\
\overline{-} \\
\overline{0.29} \\
0.44\end{array}$ & $\frac{\overline{7}}{2 \cdot 8}$ & $\begin{array}{l}{ }^{0} \\
-6(100) \\
2(100)\end{array}$ & $\overline{-}^{280}$ & $\begin{array}{l}\text { Not done } \\
=1 / 60 \\
=1 / 33 \\
=1 / 16 \\
=1 / 4\end{array}$ \\
\hline $\begin{array}{r}\text { Case } 3 \\
2(1) \\
4(1) \\
6(1) \\
19(1) \\
19(1) \\
1(2)\end{array}$ & $\begin{array}{l}\text { CSF } \\
\text { CSF } \\
\text { B } \\
\text { B } \\
\text { CSF } \\
\text { CSF }\end{array}$ & $\begin{array}{l}\overline{0.7} \\
\overline{-} \\
0.96 \\
1.23\end{array}$ & $\begin{array}{l}\bar{z} \\
\bar{z} \\
\bar{z}\end{array}$ & $\begin{array}{l}20(35) \\
196(89) \\
= \\
-35(100) \\
63(100)\end{array}$ & $\begin{array}{l}\bar{z} \\
\bar{z} \\
\bar{z}\end{array}$ & $\begin{array}{l}\text { Not done } \\
\text { Not done } \\
1 / 800 \\
1 / 25600 \\
1 / 1600 \\
\text { Not done }\end{array}$ \\
\hline
\end{tabular}


CASE 2

A previously well 9 month old baby presented with a 70 minute generalised seizure in association with fever. Her cerebrospinal fluid was normal. Thirty six hours later she developed a series of right sided seizures for which she was treated with phenobarbitone, penicillin, and chloramphenicol. A computed tomogram was reported as showing a left parietal lobe cerebritis. Transfer was arranged and on arrival she was drowsy but without focal neurological signs. An EEG was suggestive of HSE with runs of discharges particularly over the left temporal region. She was treated with broad spectrum antibiotics and acylovir, the latter at a daily dose of $1.5 \mathrm{~g} / \mathrm{m}^{2}$ from the third day of the illness for 10 days.

During her illness a mild right hemiparesis and a conjugate gaze deviation to the left became apparent. By the time of discharge she was standing independently, reaching with a left hand preference, but not smiling. Cerebrospinal fluid at discharge (day 15 of illness) showed anti-HSV titres of $1 / 33$ (titres on serum being 1/60); HSV serology was not available on samples from the beginning of the illness (table). Cerebrospinal fluid viral culture was negative. After discharge she continued to improve, beginning to recognise family members and to smile.

Seventeen days after dischage there was a sudden loss of social contact and the onset of generalised chorea. A repeat computed tomogram showed bilateral temporal lobe low densities which, on a further computed tomogram 14 days later, showed further rostral extension. An EEG showed an appreciably irregular high amplitude slow activity with frequent multifocal discharges most prominent in the temporal regions. A further EEG four weeks later was unchanged. Visual evoked responses and brain stem auditory evoked responses were normal. Further studies of the cerebrospinal fluid were performed on days 10 and 19 of the second illness (table).

Initially she was treated with anticonvulsants with no benefit and then with acyclovir followed by vidarabine as her chorea became more severe during the course of acyclovir. By the end of her antiviral treatment her clinical state remained unchanged and she was then treated with tetrabenazine, pimozide, and benztropine with some benefit. Extensive immunological investigation showed a low IgA concentration of 0.06 g/l (normal range $0.2-0.7 \mathrm{~g} / \mathrm{l}$ ), a low $\mathrm{IgG}_{2}$ concentration of $0.14 \mathrm{~g} / \mathrm{l}$ (normal range $0.35-0.87 \mathrm{~g} / \mathrm{l}$ ), and a slightly low phytohaemagglutinin stimulation response of 15.8 $\mu \mathrm{g} / \mathrm{ml}$ (normal range $>20 \mu \mathrm{g} / \mathrm{ml}$ ); all other tests were normal.

At the time of discharge she was severely handicapped with some persisting chorea and no social responsiveness, although there has been some improvement subsequently.

CASE 3

A previously well 11 month old boy was admitted to his local hospital with a 20 minute seizure after 24 hours of fever. His cerebrospinal fluid showed $20 \times 10^{6} / 1$ white cells $(65 \%$ poly- morphs) and he was treated with penicillin, chloramphenicol, and ceftazidime. Left sided seizures started and became intractable, a repeat examination of his cerebrospinal fluid showed an increased pleocytosis (table), acyclovir was started (30 mg/kg/day from the fourth day of his illness), and transfer to a tertiary centre was arranged.

On arrival he was obtunded but with no focal signs. He continued to have left sided seizures which were difficult to control. A computed tomogram showed a low density lesion with patchy enhancement suggesting infarction of the left temporal lobe and adjacent parts of the left cerebral hemisphere. Broad spectrum antibiotics and acyclovir were continued, the latter for 10 days. A repeat computed tomogram on the eighth day of his illness showed extension of the changes to include involvement of the left anterior and posterior cerebral artery territories and of the right middle and anterior cerebral artery territories. Anti-HSV antibody titres in the blood and cerebrospinal fluid were diagnostic of HSE (table). Cerebrospinal fluid viral culture was negative. From the ninth day of his illness he developed continuous choreiform movements of the left limbs.

Six days after the end of his first course of acyclovir he developed further fever and an increased pleocytosis (table), and had a further course of acyclovir this time for 14 days. Herpes serology was not repeated during his second illness.

At discharge he was visually inattentive with a right hemiplegia and a gradually resolving left hemichorea.

\section{Discussion}

The biphasic course of the illness in these children may be the result of a resurgence of the viral infection, a postinfectious neuroallergic phenomenon, or a second unrelated and coincidental illness. Extensive investigation has not showed an alternative disease entity. Immunodeficiency seems unlikely as of the two children investigated immunologically only one showed any abnormalities and these were not thought sufficient to explain the clinical course. Furthermore in none of the three children has there been a preceding or succeeding history suggestive of immunodeficiency.

The possibility of viral relapse was not supported by direct evidence of the presence of virus in the second phase of the illness as none of the children had a brain biopsy and the polymerase chain reaction for identification of HSV in the cerebrospinal fluid was not available. The serological findings in case 2 did not show a second rise in titres to support resurgent infection. However there are precedents for a resurgence of HSV that has been proved at biopsy in adults. ${ }^{1-3}$ The good clinical response to a second course of antiviral treatment in case 1 is in favour of this mechanism.

Such a hypothesis calls into question the adequacy of the initial treatment. Case 1 had dexamethasone in addition to acyclovir as part of the treatment for his initial illness and it is possible that this may have had an immuno- 
suppressant effect. Alternatively the dose and/or duration of the initial treatment may have been inadequate. All three cases were treated with conventionally adequate HSE regimens. It may be that where there is a confirmed diagnosis of HSE, a 14 day course of high dose acyclovir is more appropriate than a 10 day one.

The alternative postinfectious neuroallergic hypothesis was the presumed mechanism in the seven other non-neonatal paediatric relapses described to date as the specimens from the four brain biopsies performed showed no evidence of persistent virus (M A Carpentier-Barthez et al, paper presented at the European Federation of Child Neurology Societies, Paris 1991), ${ }^{45}$ and DNA from HSV was not identified in the cerebrospinal fluid at the time of relapse by the polymerase chain reaction in five children (M A Carpentier-Barthez et al, paper presented at the European Federation of Child Neurology Societies, Paris 1991). In our case 2 the interval of about two weeks between the two phases of the illness would be more in keeping with this mechanism, though the relapse within days of discontinuing acyclovir in cases 1 and 3 are more suggestive of resurgence of a partially treated infection. The concomitant use of dexamethasone in case 1 might also contribute to this mechanism by suppressing a vasculitic component to the initial process only to allow its emergence as the immunosuppressant effect wears off.

Given the evidence for both viral resurgence and neuroallergic activity in the relapse of HSE it seems likely that the pathophysiology of the second phase of the illness is heterogeneous. Appropriate treatment therefore remains problematic depending as it does on identifying the nature of the process in the individual child. Serological tests do not discriminate rapidly or reliably enought to aid therapeutic decisions. Brain biopsy for culture of HSV would also be too slow as it may take up to three weeks to grow in this situation. Identification of antigen or DNA in biopsy material would not be sufficient to distinguish between active infection and a postinfectious phenomenon, though its absence from affected brain or cerebrospinal fluid would argue for the latter. Biopsy histology might be helpful but only if brain involved in the second phase of the illness was sampled and the current process identified as either a necrotising encephalitis or a vasculitic picture with perivascular demyelination. Depending on the findings treatment might then include either further acyclovir with or without vidarabine or immunomodulatory treatment such as corticosteroid.

Finally it is of note that two of our three patients relapsed with florid chorea as did all seven of the children with HSE relapse described elsewhere (M A Carpentier-Barthez et al, paper presented at the European Federation of Child Neurology Societies, Paris 1991). ${ }^{45}$ Case 3 exhibited choreiform movements during the intitial phase of the illness. Chorea in association with an encephalopathic illness should raise the possibility of HSE or, in the appropriate context, of HSE relapse.

1 Davis LE, Maclaren LC. Relapsing herpes simplex encephalitis following antiviral therapy. Ann Neurol 1983;13:192-5. 2 Dix RD, Baringer JR, Panitch HS, Rosenberg SH, Hagedorn J, Whaley J. Recurrent herpes simplex encephalitis: recovery of virus after Ara-A treatment. Ann Neurol 1983; 13:196-200.

3 VanLandingham KE, Mantellar HB, Ross GW, Hayden FG, Ross GW, Hayden FG. Relapse of herpes encephalitis after conventional acyclovir therapy. JAMA 1988;259:1051-3.

4 Abramson JS, Roach ES, Levy HB. Post-infectious encephalopathy after treatment of herpes simplex encephalitis with acyclovir. Pediatr Infect Dis 1984;3:146-7.

5 Barthez MA, Billard C, Santini JJ. Relapse of herpes simplex encephalitis. Neuropediatrics 1987;18:3-7.

6 Maxwell GM, Thong YH, Manson JL, Robertson CF. Herpes simplex encephalitis treatment with adenine arabinoside and cytosine arabinoside. Med J Aust 1978;1: 181-3. 